\title{
Evaluating the Effectiveness of the Nuclear Suppliers Group: A Functionalist Perspective on the Regime
}

\author{
Jinwon Lee
}

The Nuclear Suppliers Group was established to implement and enforce the Nuclear Non-proliferation Treaty. Compared to research on the NPT, there are few studies illustrating the origins or effectiveness of the NSG. This paper is designed to meet the need for more substantive analysis focusing on the NSG. To analyze the effectiveness of the NSG, three areas were examined: legal liability, reduced transaction costs, and clear and transparent information systems. As a result of analyzing these three issues, substantial evidence exists that the NSG will be maintained and continue to work effectively to reduce the transaction and information costs; furthermore, high issue density of the NSG and its role in providing forums and meetings for negotiations also effectively reduces transaction costs. In addition, the NSG's various information sharing systems, its regular meetings of technical experts, and the active participation of information-strong states has become a stepping stone to reducing the uncertainty and strengthening the NPT's effectiveness. However, there are important limitations to the NSG's effectiveness. There are several exceptional cases, such as China and Russia's export cases, that have harmed the integrity of the NSG regime. In addition, the membership extension issue has become a dilemma for the NSG. It is deemed necessary to initiate talks with non-membership states to achieve the long-term goal of non-proliferation, but this hinders optimization in terms of membership. Those limitations mitigate the effectiveness of the regime. Thus, it is necessary for the NSG to provide clear standards for full membership of the group and to clearly interpret the particular clauses of NSG guidelines.

Key Words: Nuclear Suppliers Group, non-proliferation, regime theory, functional theory, nuclear energy

\footnotetext{
*Jinwon Lee (jiwolee16@mofa.go.kr) serves as a researcher at the Institute of Foreign Affairs and National Security at the Korea National Diplomatic Academy. She received her B.A. in political science and an M.A. in international peace and security from Korea University. The author wishes to thank Professor Yim Man-Sung and Jun Bong-guen for providing the opportunity to expand on an early analysis of the NSG and non-proliferation regimes. The author also is grateful to the three anonymous reviewers for their comments.
} 
$\mathrm{I}$ nternational society is faced with the perils of the proliferation of weapons of mass destruction, especially nuclear weapons. North Korea declared itself a nuclear-weapon state in 2017. This claim by Pyeongyang is in violation of the Nuclear Non-Proliferation Treaty's (NPT) foundational precept that there should only be five nuclear-weapon states, and the proliferation of nuclear weapons should equally be banned and proscribed. North Korea's development of nuclear weapons has threatened not only security in Northeast Asia but also the effectiveness of international WMD non-proliferation regimes.

Unfortunately, North Korea is not the only country that has reneged on the agreement creating the international nuclear non-proliferation regime. Iran is a member of the NPT, but was found in non-compliance with the treaty. Moreover, India, Pakistan, and Israel are not under the NPT's control because they have not signed the agreement, and those countries are highly castigated for their suspected involvement in nuclear proliferation. Considering the serious violations of international non-proliferation rules by several countries, does this force the conclusion that non-proliferation regimes have failed and were supported in vain? This research strongly suggests that the answer is 'No.' Albeit, there are some limitations and difficulties involving the handling of recalcitrant countries, but the regime has proven successful in addressing nuclear weapons proliferation.

Since the emergence of the NPT in 1968 and the creation of additional non-proliferation compliance organizations such as International Atomic Energy Agency (IAEA) and Nuclear Suppliers Group (NSG), interntional nonproliferation regimes have been evolving. Non-proliferation regimes such as the NPT, IAEA, and the NSG have been expanded through the accession of member states and the holding of annual meetings. Effectiveness has been commensurate with the evolution of those regimes; the emergence of nonproliferation regimes not only have influenced many member states' decisions to refrain from developing military applications of their nuclear energy programs, but this also has helped to delay some recalcitrant nations from developing their nuclear-weapon programs (Sagan 2011). Notwithstanding some scholars and policy-makers' skeptical perspectives on non-proliferation regimes, many others find strong evidence that security-related treaties such as the NPT restrain states from pursuing policies they might otherwise prefer. According to the Sagan (2011) studies, the IAEA created an inspection mechanism that led governments to monitor their own scientists and the growth of the nuclear energy sector. Each member state favors compliance with treaty obligations because the cost of disobeying treaties would be higher if strong sanctions were imposed. Moreover, it is commonly accepted that domestic politics might also aid in the treaty's 
effectiveness. The NPT promotes the responsible use of nuclear technology to meet domestic energy needs. If NPT norms are widely accepted by both civil society and the operators of nuclear power plants, those actors would be able to pressure political leaders to remain in compliance (Sagan 1996/1997). Based on empirical testing of a sample of countries from different years, a recent study by Fuhrmann, Matthew and Yonatan Lupu $(2016,24)$ concluded, "NPT ratification significantly reduces the probability that states will seek nuclear weapons".

After surveying the literature on the non-proliferation regimes described above, it is reckoned that there are several outstanding papers dealing with the NPT but far fewer studies illustrating the origins or effectiveness of the NSG. This international institution created to manage export controls is a crucial component of the regime to prevent the proliferation of nuclear weapons. Export control is an effective tool to delay development of nuclear weapons through prevention of the exporting of important goods and technologies to suspicious states that are highly likely to renege on the regime's norms and treaties. In addition, NSG is an excellent organization for coordinating decisions about which states are able to receive what kinds of nuclear technologies. In this light, the NSG is also one of the crucial elements in the non-proliferation regime; thus, it should not be ignored in academia (Sagan 2011).

Considering the necessity and importance of studying the NSG, this paper will focus primarily on the export control regime by addressing three questions related to the NSG's origin and effectiveness. First, why was the NSG established and how has it been developed as one of the major components of the nonproliferation regime? Next, why should functional theory, among the various regime theories, be applied to explain the effectiveness and maintenance of the export control regime? And finally, how do those categories introduced by functional theory help us to evaluate the effectiveness of the NSG? To analyze and evaluate the NSG's effectiveness, the first part of this paper selects and establishes the criteria and standards of regime effectiveness by incorporating Keohane's (1982) functional theory. The second section of the paper explains and evaluates the NSG's effectiveness in establishing selected standards. Finally, specific policies are suggested that could help the NSG become much more effective.

\section{EVOLUTION OF THE NSG AND NON-PROLIFERATION REGIME}

After the discovery of nuclear fission and the development of nuclear weapons, it was proposed that an international agency be created to control nuclear 
materials and technology and to prevent the spread of nuclear weapons. Moreover, the US decision to use atomic bombs on the Japanese cities of Hiroshima and Nagasaki in August 1945 were alarming events to other countries. The seismic outcome of nuclear bombing frightened international society, and a voice to control those nuclear weapons had been raised. After 30 years of effort on the part of nuclear scientists and political leaders to produce an international institution or agency to manage nuclear proliferation, the NPT was negotiated in 1968. Moreover, the IAEA was created in 1957 in response to deep fears of the misuse of nuclear technologies and the necessity to handle new nuclear technologies in peaceful ways. A non-proliferation regime was expected to shape how countries behave. Rathjens's (1998) study found that the NPT and IAEA established these basic principles of non-proliferation:

(1) Nuclear-weapon states would not assist other countries to acquire nuclear weapons;

(2) Non-nuclear-weapon states would agree that they should not acquire nuclear weapons;

(3) The facilities in the non-nuclear-weapon states producing fissionable materials that are usable to produce nuclear weapons should be subject of surveillance by the IAEA (26).

In view of the above findings, the development of international treaties and agencies such as the NPT and IAEA was conducive to mitigating the fears of nuclear weapons through proscribing the proliferation of nuclear weapons and through trying to limit access to nuclear materials and technology with strong surveillance by the IAEA. Numerous states acceded to joining the treaty, although four UN member states-India, Israel, Pakistan, and South Soudanhave never been members of the NPT. Even though some UN members chose not to participate, the NPT has become the cornerstone of the international nonproliferation regime. According to Keohane (1982, 352), the explicit purpose of the non-proliferation regime is "keeping nuclear material and knowledge from diffusing rapidly to potential nuclear powers ". To achieve this goal, each component of the non-proliferation regime has its own specific purpose: the NPT aims at preventing the wider dissemination of nuclear weapons, and the NSG encourages states to adopt nuclear export controls to assist in the implemention and enforcement of the NPT. If the NSG was developed to support the NPT then what were the specific cogent reasons for its creation?

The NSG is one of the most crucial non-proliferation organizations, establishing guidelines for transferring nuclear-related materials, equipments, 
and technology. Since cutting-edge nuclear technology is necessary to develop nuclear weapons, restricting the dissemination of those technologies is one of crucial goals for non-proliferation. In addition, preventing the spread of nuclear materials to countries suspected of developing nuclear weapons is another means of delaying their development plans. To control the export of both technologies and materials to be used to build nuclear weapons, the NSG emerged as an instrument to strengthen the non-proliferation regime. The trigger for forming the NSG was India's nuclear test in 1974. The United States, Germany, France, the United Kingdom, Japan, Canada, and the Soviet Union established the NSG to restrict nuclear commerce and coordinate nuclear export controls among state. India was not an NPT signatory, but a bilateral nuclear cooperation agreement with Canada and United States enabled India to be supplied nuclear reactors. Those imported reactors were assumed to be used merely for peaceful purpose (Thränert and Bieri 2013); however, India used those reactors to eventually develop and test a nuclear weapon. This case of India in 1974 prompted those countries of the 'nuclear club' to create the NSG, as India was a timely alarm that the NPT alone would not deter proliferators. Non-proliferation was seen as being contingent on the close coordination among supplier countries and strict export controls of nuclear materials and technology. The NSG was formed on the premise that the NPT's Article 3.2 was not enough to prevent the illegal transferring of nuclear technology and materials, so the NSG was necessary to implement Article 3.2 in an effective manner. Article 3.2 of the NPT states:

Each State Party to the Treaty undertakes not to provide: (a) source or special fissionable material, or (b) equipment or material especially designed or prepared for the processing, use or production of special fissionable material, to any non-nuclear-weapon State for peaceful purposes, unless the source or special fissionable material shall be subject to the safeguards required by this Article.

The NSG's first major achievement was approving guidelines for exporting nuclear materials and equipment for the group's 15 members, which was expanded from the original group of seven countries. The first guidelines suggested common criteria for technology transfers of sensitive items related to uranium enrichment, special controls on items for uranium enrichment, and spent fuel reprocessing (Hibbs 2011). The NSG published its guidelines, but the strict export control of nuclear materials and technology was not achievable and the NSG itself did not organize regular meetings for another 13 years. The 
only change between 1978 and 1991 was that the NSG's membership increased from 15 to 27. The NSG's 1991 meeting was triggered by the revelation of Iraq's procurement program after the first Gulf War. The 1991 meeting was initiated by the apparent detection of a clandestine nuclear-weapon program in Iraq, so this NSG meeting led to meaningful changes.

First, NSG member states agreed to holding regular meetings after the 1991 meeting. To coordinate controlling nuclear materials and high-end technology, 'regularity' became a prerequisite for the member states, which saw the necessity of discussing what items were to be controlled for, while also updating NSG's guidelines. According to the Public Statements of the Warsaw meeting held in 1992 (Nuclear Suppliers Group, 1992), "The participants agreed upon the need for regular consultations and decided to convene another meeting within the next year". Annual meetings have been held since 1991, and this regular meeting has been conducive to leading NSG to extend the scope of its rules for global trade in nuclear technology and materials.

Another crucial change was to extent the NSG's rules for export controls beyond the mandate of the NPT. The NSG's original role was updating and publishing lists and guidelines. After the guidelines for the export of nuclear materials, equipment, and technology was adopted in 1978, the NSG contributed another set of guidelines for nuclear exports and nuclear materials-related exports by adopting guidelines in 1992 for transfers of nuclear-related dual-use equipment, materials, software, and related technology. The second part of the NSG guidelines strongly encouraged suppliers to make delicate judgments when they exported nuclear-related dual-use equipment, materials, and technologies to states with the desire to illegally develop nuclear weapons. Newly-developed high-end technologies enabled states to use products and technologies for both civilian purposes and military applications. The NSG guidelines' dual-use list exhorted member states to strictly prohibit the export of controlled dualuse commodities and technologies. In addition, the NSG started updating the lists and extending list items after adopting the 1992 guidelines. Updating the list was seen as crucial to the enforcement of effective measures to prevent the proliferation of nuclear weapons, since technology was developing quickly. The NSG's participating states reached consensus in 2004 to adopt a catch-all mechanism that would act as a higher-quality control system on sensitive enduse materials and technologies (Hibbs 2011). This catch-all system called for member states and trading companies to examine specific recipients and end uses of specific commodities much more thoroughly and control unlisted items to be used in a sensitive way.

Lastly, the number of states participating in the NSG has expanded as well. 
As of October 2017, 48 states are participating in the NSG. The number of participating states is crucial for the implementation of the NSG guidelines since its system is based on each member state's efforts to obey the rules and guidelines. Also, for strengthening the catch-all system, member states must make objective judgments on items to be exported so that they correspond to the NSG's guidelines. China joined the NSG against the backdrop of membership expansion. Since China is one of the crucial nuclear suppliers exporting nuclear materials and equipment and one of the officially recognized nuclear-weapon state, China's participation in the NSG has been a meaningful milestone to strengthening the nuclear export control regime, especially if China carefully reviews and employs the NSG guidelines. That membership quadrupled was a function of the NSG's desire to bring all nuclear supplier states under international guidelines (Hibbs 2011). This relates to one of the most salient questions of this paper: how to maximize benefits through the institutionalization of a nuclear export control regime? Does the export control regime effectively prevent the proliferation of nuclear weapons? To answer those questions, establishing criteria and standards to analyze the NSG thoroughly will be addressed in the last part of this paper.

\section{REGIME THEORIES AND FUNCTIONALISM}

Quantitative methods are widely used for analyzing the costs and benefits of certain behaviors. The effectiveness of regimes is also frequently analyzed using primary and secondary sources of data. After reviewing the literature, there are numerous papers examining the effectiveness of the NPT using statistical data. ${ }^{1}$ However, is it inappropriate to follow the same path as previous scholars to thoroughly analyze the NSG? The major obstacle to applying quantitative methods to an analysis of the effectiveness of the NSG is that there is not enough open source statistical data to document the effectiveness of export controls. Since the export control regime is directly linked to each member state's exports, it is hard to access each state's controlled or confidential export data to analyze the effectiveness of the NSG. Moreover, the export control regime's rules are not legally binding and each member state is called upon to merely try to abide by the regime's rules. It is difficult to collect each state's data on how much material was restricted and what markets shifted under the rules of the NSG. The relative dearth of statistical data on the NSG makes analysis based on a strong

\footnotetext{
${ }^{1}$ See Fuhrmann and Lupu (2016).
} 
theoretical framework crucial. A review of regime theories and their insights may assist in the design of standards and criteria to elicit meaningful analysis of NSG effectiveness from what literature and data is available. This section focuses on finding out what is the most logical and felicitous theory to allow for valid and reliable analysis of the effectiveness of the NSG, the organization at the forefront of the international export control regime.

There are three major regime schools of thought: structuralism, gametheoretic approaches, and functional theories. The three either make different assumptions about regimes or take different approaches to analysis, but collectively they make up what is known as the study of 'International Regimes.' Those theoretical schools have explicated how regimes are created, expanded, and sustained in international society. Each of the three has particular strong points with regards to explaining regime creation, the conditions which enable cooperation in regimes, and what are the effects or facilitating roles of regimes. Before studying each, it is necessary to define what is meant by regime effectiveness. Once we have defined 'effectiveness,' it will be possible to answer the question of which is the most logical to explain regime effectiveness.

There are a variety of approaches elucidating the meaning of regime effectiveness, and regime effectiveness is construed differently by various analysts. There are legal definitions, policy-oriented definitions, and political definitions. From a legal point of view, the effectiveness of regimes is measured by the degree to which conflicts are regulated by the rule of law. A policyoriented definition strongly underlines efficiency of command and control regulations to achieve some set of well-defined policy goals specified by the regime. Lastly, the most widely employed definitions are related to political conceptualizations: regimes are viewed as causing changes in behavior and the patterns of interactions of participating states that leads to successful management of targeted problems and what member states are faced with becomes semi-institutionalized (Levy et al. 1995). In sum, all the definitions of regime effectiveness show a causal relationship between the regime's rules, regulations, and institutions, and relevant changes in international behavior (Levy et al. 1995).

Based on the definition of regime effectiveness, which class of regime theory is focused on explicating the causal connection between the regime and related behavior changes? First, regime theory is to be analyzed with respect to structuralism, illustrated by the theory of hegemonic stability. This theory is the most widely applied to explain regime dynamics. It has a parsimonious model and logical causation in its argument (Haggard and Simmons 1987). The theory underlines the role of the hegemon in the regime; public goods provided by the 
hegemon are strongly correlated with regime creation, maintenance, and the weakening of the regime. According to the structuralist explanation, public goods are what the dominant powers provide in the international regime to encourage other states to obey the rules, norms, and decision-making procedures that the hegemon creates and tries to enforce. In this sense, regimes are constructed and maintained by the hegemon's ability to influence. ${ }^{2}$ This causal correlation model is parsimonious, but it is not useful as an explanation for the effectiveness of the regime. Rather, it is focused on explaining the regime's creation; and, it is hard to substantiate the logical linkages between the global goals of a single powerful hegemon and behavior changes in member states. In addition, hegemonic stability has been empirically rebutted by the fact that not all regimes are created and sustained by a single powerful state's existence. Regimes were created and sustained during the 'bipolar' Cold War era, and most regimes have been shown to promote collective cooperation to build regulations and rules by states seeking collective goods rather than by a single powerful hegemon dictating rules and norms by fiat (Haggard and Simmons 1987). The nuclear non-proliferation regime embodied in the NPT and the NSG also emerged during the Cold War "bipolar" era, in 1968 and 1974. In addition, NSG's decision process is based on consensus: a particular action would be granted only if all member states agreed. In this sense, the theory of hegemonic stability will not adequately address the question of the effectiveness of the non-proliferation regime in general, and the NSG in particular.

Game theoretic approaches have thrown new light on the conditions conducive to regime creation and have helped to explain why states cooperate in an anarchic international system. The applications of game theory to international regime studies assumed the simplified 2x2 game structure and the prisoner's dilemma model. Game theory has a strong linkage with microeconomics, so that explanations based on game theoretical approaches have a simple structure and restrictions on various variables, such as discrete actors in domestic and international politics. The prisoner's dilemma underlined a paradox precipitated when individual actors are not able to communicate and cooperate to maximize benefits. Thus, each player acting in his own self-interest does not result in the ideal outcome for either under a prisoner's dilemma negotiation situation. The game theoretic idea applied in the study of international regimes suggests conditions needed to diminish the impact of the prisoner's dilemma situation by developing networks of complex interdependence and recognizing

\footnotetext{
${ }^{2}$ See Kindleberger (1973) and Snidal (1979) for a substantive explanation of how hegemonic stability can facilitate a particular type of international cooperation.
} 
the continuousness of games among players. In this sense, the features of international regimes, such as networks and continuous communication among actors under each regime's structure, would be a particular condition to the creation of regimes (Haggard and Simmons 1987). The idea of game theory is simple and clear, but the idea's oversimplification elicits both risks and benefits for theory-building. The simplicity of the model yields logical and parsimonious explanations, but at the same time, it is merely able to explain a particular facet of the regime: the conditions enabling cooperation at the early stages of regime formation. In other words, game theory is not always able to tell us which equilibrium will be reached as a valid set point. From the point of view of regime studies, the question remains how regimes will be institutionalized and how institutions will develop and enforce norms and rules. In this sense, game theory is tangential to explicating the causal relationship between the regime's rules, regulations, institutions, and the behavior changes and effectiveness of the regime. Functional theories are viable alternatives to supplementing the blindspots in game-theoretical approaches.

The theories above focus on articulating how international regimes are able to be created and under what conditions international regimes could emerge. On the other hand, functional theories explain why a regime's member states would be complaint to the rules, regulations, and norms established by consensus under the regime's structure. The functional idea of the regime strongly underlines how regimes can be maintained, even though the conditions facilitating the regime's creation had disappeared (Keohane 1984). In this sense, functional theories do not merely explicate the reasons for regime creation, but also try to explain actor behavior or institutional development in terms of effects. Functional theories are related to problems of market failure and the use of Coase theorem. According to Coase, a legal framework establishing liability, perfect information, and zero transaction costs is crucial to leading actors to choosing solutions that are Pareto optimal (Keohane 1984). However, those conditions are not perfectly met in 'real world' politics, so it is hard to apply directly the economic terms to interpret international regimes. An inversion of the Coase theorem would be a meaningful and appropriate approach to interpreting international regimes. Functional theories classify the inversion of the Coase theorem as facets and features of regimes leading actors to comply with established rules and norms. In this view, there are interesting implications of what functional theories suggest about international regimes: international regimes are effective when there are patterns of legal liability influential to actors, and regimes are able to reduce transaction costs and information-asymmetry among those actors. Legal liability, reduced transaction costs, and transparency (clear and transparent 
information systems) allow actors to overcome market failures and lead them to choose Pareto optimal solutions. If international regimes provide the conditions for what the Coase theorem suggests are optimal then actors will comply with the regime's rules and regulations to maximize their benefits. When particular regimes meet the conditions of what an inversion of the Coase theorem would suggest, the regime will be able to effectively change state behavior under guidelines set and enforced by international institutions. In this light, the functionalist idea about international regimes is the most appropriate theoretical framework to analyze regime effectiveness. Using the following categories of legal liability, transaction costs, and transparency suggested by an inversion of the Coase theorem, the export control regime embodied in the NSG will be evaluated. The effectiveness of the NSG will be analyzed by each category in greater detail in the next section.

\section{FUCTIONAL THEORIES OF REGIMES AND THE NUCLEAR SUP- PLIERS GROUP}

In this part, the categories of legal liability, transaction costs, and information (uncertainty issue)-what Keohane suggested to analyze the effectiveness of regimes-will be applied to evaluate the effectiveness of the Nuclear Suppliers Group. Below, how the categories of each dimension can be used to evaluate the NSG, and the export control regime it represents, will be discussed in turn.

\section{THE NSG'S EFFECTIVENESS AND LIMITATIONS: AN ANALYSIS OF LE- GAL LIABLILITY}

The strong legal liability of international regimes obviously requires accountability. Nation-states participating in the regime have to be held 'accountable' for complying with the rules and regulations, and other participants under the regime are mutually expected to be compliant with those rules. Then, how should this criteria suggested by Keohane be applied to analysis of the NSG's effectiveness? Sub-criteria under the rubric of 'legal liability' are necessary in light of the export control regime. Keohane and Victor (2011) suggest sub-criteria for assessment with regards to each international regime's distinct characteristics, and another paper focuses on establishing general substandards for the sake of assessing regime legitimacy (Buchanan and Keohane 2006). The sub-criteria in this paper are selected among various substantive standards suggested in those papers in accordance with both the NSG's specialty 
and its general institutional role as part of the export control regime. ${ }^{3}$

First, the ability of the regime to impose sanctions would be one of the substandards to assess the effectiveness of the NSG. Since the NSG is one part of the 'export control regime' to prevent the proliferation of nuclear weapons, participating in the regime would be directly correlated with the restriction of the member state's exports of technology and materials. In other words, the member state's economic gains and the value of free trade are likely to be affected. Notwithstanding those costs of participating in the NSG, states created the regime to effectively manage the issue of proliferation. In this complex situation, the ability to impose sanctions is necessary to offset the costs of being part of the regime. The accountability of the regime would be assured only when those participants are sharing a strong belief that recalcitrant states should be punished by sanctions.

Next, institutional integrity is also one of the sub-criteria for assessing the legal liability of the NSG. If a regime shows a pattern of disparity between its substantive rules or regulations and actual practices, the accountability of the regime and its effectiveness could be thrown into question (Buchanan and Keohane 2006). One of the major goals of the NSG is establishing guidelines for member states, and those guidelines help to prevent the export of nuclearrelated materials, equipment, and technology. If the deficiencies and lack of integrity in the NSG is not corrected, those guidelines would be useless and nugatory and the export control regime would not achieve its ultimate goal, preventing the proliferation of nuclear weapons. In this light, assessing the integrity of the institution and the regime is meaningful to assessing the effectiveness of the regime.

Lastly, coordination of the laws and practices of dozens of governments is also highly necessary. Member states are strongly required to fulfill the regime's responsibilities at the domestic level. In other words, each member of the regime should reinforce its own rules and regulations and internalize the regime's ideas in their government's norms and rules. This sub-criteria results from the consideration of the export regime's distinctive character: major 'exporters' are usually private firms and enterprises. Thus, government efforts to pressure firms that operate within their sovereign territory to comply with NSG guidelines and rules, and educate them thoroughly about those rules and guidelines, is a

${ }^{3}$ The climate change regime and its complexity were analyzed in consideration of regime characteristics (Keohane and Victor 2011), and sub-criteria to access each regime's legal liability were introduced in another study by Buchanan and Keohane (2006). Those two different approaches for the sake of assessing international regimes will be used in this paper instead of taking one side to analyze regime effectiveness. 
crucial element to enhancing the effectiveness of the export control regime. The effectiveness of the NSG and high accountability of the regime is not achievable without the enactment of new domestic rules and laws in line with NSG guidelines. The last part of this section will analyze the NSG's legal liability in specific reference to the sub-criteria selected above.

Table 1 below elucidates the most sanguine points for evaluating the effectiveness of the NSG and the limitations hindering the development of the export control regime. The NSG's achievements and current challenges are listed in the table with the selected sub-criteria.

Table 1. Legal Liability: How to Increase Regime Accountability

\begin{tabular}{|c|c|c|}
\hline & + (Effectiveness) & - (Limitations) \\
\hline $\begin{array}{l}\text { The Ability to } \\
\text { Impose Sanctions }\end{array}$ & $\begin{array}{l}\text { - NSG membership includes all veto } \\
\text { powers of UNSC in NSG } \\
\text { - Placing embargoes on recalcitrant } \\
\text { countries and encouraging member } \\
\text { countries to do the same way }\end{array}$ & $\begin{array}{l}\text { - Discretion of the exporting country to } \\
\text { approve certain exports } \\
\text { - No effective attempt to impose } \\
\text { an embargo against a recalcitrant } \\
\text { country (NSG lifted embargo on India } \\
\text { in 2008) }\end{array}$ \\
\hline $\begin{array}{l}\text { Institutional } \\
\text { Integrity }\end{array}$ & $\begin{array}{l}\text { - NSG established and revised } \\
\text { guidelines } \\
\text { - NSG has updated the trigger list and } \\
\text { compiled a new control list of dual- } \\
\text { use items. }\end{array}$ & $\begin{array}{l}\text { - China's exports to Pakistan } \\
\text { (Grandfather Clause) } \\
\text { - Russia's nuclear exports to India } \\
\text { (Safety Exception) }\end{array}$ \\
\hline $\begin{array}{l}\text { Reinforcing } \\
\text { Domestic Rules } \\
\text { and Regulations }\end{array}$ & $\begin{array}{l}\text { - Growing number of states } \\
\text { harmonizing national export control } \\
\text { system with the NSG Guidelines and } \\
\text { Control Lists (e.g. China updated } \\
\text { nuclear export regulations after } \\
\text { joining NSG in 2007) } \\
\text { - NSG's legal advice or model } \\
\text { regulations for member states (NSG's } \\
\text { efforts to provide various models for } \\
\text { domestic law and regulation) }\end{array}$ & $\begin{array}{l}\text { - NSG itself does not detect or approve } \\
\text { the exports of each state } \\
\text { - Internalization of NSG rules hinges } \\
\text { upon the willingness of member } \\
\text { states }\end{array}$ \\
\hline
\end{tabular}

Apropos 'the ability to impose sanctions' criterion, the participation of China has been a keystone to strengthening the NSG's accountability. China's participation is meaningful in light of the inclusion of all veto powers of the United Nations Security Council in the NSG (Hibbs 2011). Since NSG is the export control regime, it is available to ban a recalcitrant state's nuclear trading 
and to place an embargo upon the state for nuclear materials described in the trigger list of the NSG. It is generally understood that all the members of the NSG do not make formal decisions to boycott particular countries without a consensus; but, it is logical to assume that any member state whose policies call for an embargo would be able to encourage and persuade other member states to place an embargo upon a particular country in the NSG's annual forum (Nuclear Suppliers Group 1999).

However, the NSG itself does not have the ability to punish and impose sanctions against recalcitrant countries, as illustrated in the UN Charter. In this light, NSG membership, with all Permanent- 5 members of the Security Council included, is expected to develop possibilities for cooperation on the nonproliferation issue in the UN Security Council. China's participation beginning in 2004 became a crucial milestone for the NSG to prevent proliferation of nuclear weapons and strengthen the NPT in the long-run.

The participation of all $\mathrm{P}-5$ countries under the regime is a positive point for the NSG; the question of the NSG's ability to impose sanctions is still left as unsolved, showing a few limitations of the institution. Albeit, there are strong points about the NSG, that it prevents recalcitrant states from obtaining nuclear fuel, materials, and technology, but the NSG's decision on whether to approve exports to particular countries totally relies on the exporting country's discretion to follow or enforce that decision. NSG members' ban on nuclear trades with particular countries is totally dependent on each country's willingness to strengthen the regime and prevent proliferation. Moreover, the attempt by NSG member states to place embargoes upon India revealed several institutional limitations of the export control regime. NSG member states have constrained India from obtaining nuclear fuel, materials, and technology by trade, but India still developed atomic bombs in secret and conducted its first nuclear test in 1974. On the contrary, the NSG's embargo against India rather precipitated India's efforts to develop its own nuclear technology (Paddock 2009), and the NSG even lifted its long-time embargo on nuclear trade against India in 2008. Albeit, the decision on lifting the embargo on India was made for achieving the widest possible implementation of the NSG's guidelines, it was still seen as a certain limitation of the regime. The NSG was not able to impose effective sanctions against disobedient states such as India. Rather, member states of the regime adopted a statement by consensus exchanging India's implementation of the guidelines for withdrawing the embargo against the country.

There also are both positive and negative aspects of regime effectiveness in light of the second criterion, 'institutional integrity.' The NSG established guidelines for nuclear transfers and trade, and this is a crucial achievement of the 
NSG to improve its institutional integrity. The first set of NSG guidelines focused on clearly defining the standards of implementation, which is an essential responsibility of all member states of the NSG. According to the guidelines, nuclear suppliers should transfer trigger list items or related technologies to a non-nuclear-weapon state and for peaceful use only. The NSG also has updated its trigger lists concomitant with the development of nuclear technology, and it has compiled new control lists of dual-use items. As technology and equipment have developed, some technologies and goods are able to be utilized for both civilian and military applications. In this sense, there is a strong necessity to control dual-use items and technologies, and so the second set of NSG guidelines established controls for exporting nuclear-related dual-use items and technologies. The trigger list, which all member states are required to comply with, has become a great pillar of the NSG's institutional integrity.

However, there are two major cases of attempts to circumvent the guidelines and claim exceptions: China's nuclear exports to Pakistan and Russia's nuclear trade with India. When the first set of guidelines was published, it allowed two exceptions: a Grandfather Clause and a Safety Exception. Those clauses have been interpreted differently as a means of abusing the exceptions in the guidelines. They are also possibly significant loopholes to the assurance of institutional integrity (McGoldrick 2011). Beijing insisted that trading nuclear reactors with Pakistan, which is not an NPT signatory, was available and could be waived because Chinese contracts with Pakistan were in place before China joined the NSG. Considering that Pakistan was under the auspices of the IAEA, China's decision to export nuclear materials caused the NSG to become seriously ensnared in an accountability problem (Thränert and Bieri 2013). Moreover, Russia also has exploited the 'exceptions' to justify its contracts with India. Moscow first tried to justify its exports to India citing the Grandfather Clause. However, NSG member states rebutted Russia's claim and insisted that the agreement between Russia and India was not subject to the Grandfather Clause exception. After failure to justify sales to India, Moscow attempted to export lowlevel enriched uranium to India citing the Safety Exception (McGoldrick 2011). Notwithstanding strong objections from other NSG members, Russia delivered nuclear fuel to India. Those cases show that there is room to differently interpret the rules and regulations of the export control regime, resulting in inconsistent practices and implementation (Blackford 2005). These exceptions also are regarded as severe loopholes in the institutional integrity of the NSG.

Finally, each member state of the NSG should fulfill the regime's responsibilities to efficiently curb the illegal trade in nuclear materials and technologies. To achieve the NSG's ultimate goal, it is necessary to strongly 
reinforce each country's domestic rules and regulations and see them internalized. Effective export controls are available when both the government and private sector comply with NSG guidelines and rules. The NSG offers advice to member states for the sake of promoting that member state's adherence to the guidelines. The NSG's outreach activities and legal advice or model regulations for the member states are helpful to newly-joined member states to encourage them to be compliant with the NSG's guidelines.The NSG has provided various models and best practices for domestic law and regulation. And, since the NSG's member states have kept registered on the Point of Contact, the NSG is able to offer its legal assistance at very reasonable costs. The NSG's fellowships for customs agents and licensing officers are also considered an effective means to promoting the NSG's guidelines at the domestic level (Nuclear Suppliers Group 1997).

It is a sanguine point that a growing number of states has harmonized their national export control systems with the NSG guidelines. China's participation in 2004 and its efforts to update nuclear export regulations in 2007 would be specific examples. After a 10-year silence, Beijing revised its domestic regulations to provide explicit guidance for actors involved in the nuclear trade. The updated regulations underlined the necessity of proper documentation of every exporter's shipment. Chinese exports were requested to comply with the new customs regulations. Moreover, categories of the specific penalties for the export control violations were illustrated (Kerr 2007). Chinese revision of its domestic regulations shows a positive trend for the export control regime, and it would be conducive to strengthening the regime's accountability.

Notwithstanding the NSG's efforts to reinforce the domestic laws and rules of member states in line with the NSG's control list, the major problem in this area also is the issue of 'discretion' among member states. A particular state can become a member of the NSG, but the NSG is only able to promote updating domestic regulations and to give advice on revision of a member state's domestic customs and export control system. The NSG itself does not scrutinize or approve each state's exports of nuclear materials and technologies. In light of this, internalization of the NSG's rules hinges upon the willingness of member states, and this will continue to be a limitation to the NSG becoming an effective regime in the long-run.

NSG'S EFFECTIVENESS AND LIMITATIONS: AN ANALYSIS OF TRANSATION COST

To evaluate the effectiveness of the NSG thoroughly, it is necessary to define sub-criteria to analyze and review how to reduce transaction costs under the 
NSG regime. Reduced transaction costs are a crucial factor to improving the effectiveness of the regime. Keohane (1982) introduced several conditions for maintaining regimes at lower transaction costs. According to Keohane, three specific sub-criteria to reduce transaction costs are elucidated. First, the concept of 'issue density' is introduced as a useful concept to answer the question of which circumstances do regimes meet the conditions to lower transaction costs? There is a causal correlation between the number or importance of issues and the maintenance or effectiveness of the regime. If particular issues are shown to have complex linkages or are especially crucial to particular actors, they are rarely resolved by mere bilateral or ad hoc agreements. In this sense, when issue density is high, it is more likely for the demands on regimes will be raised and frameworks of rules, norms, and regulations to resolve issues in an economical way will be developed, and there will be a strong possibility that the regime will work effectively and be well maintained. Negotiations on complex and important issues under a regime are the most effective way to resolve issues. This is because the regime and its framework bring actors together and make them consider the whole complex issue at the same time (Ibid.). In light of this, it is crucial to analyze the characteristics of the issue and what the NSG handles under its regime. If issue density is high, the export control regime is highly likely to be effectively maintained.

Providing negotiating frameworks and forums is another sub-criterion used to analyze how to reduce transaction costs and improve the effectiveness of the NSG. The idea is introduced as a condition to reducing transaction costs. Specific examples of this can be found in international economic regimes (Keohane 1984). Providing forums would be a specific standard to consider when evaluating the effectiveness of the NSG. Various actors, such as international organizations, global corporations, and governments, are subsumed into international economic regimes, and those regimes provide forums for negotiation to promote international trade and build frameworks for free trade. Systematic and regular meetings have acted as a catalyst to making agreements among diverse actors. The logic to explain the effectiveness of international economic regimes is also applicable to analysis of the export control regime as well. A systematic and organized framework to provide regular chances for negotiation raises the effectiveness of regimes.

The optimal size of a regime is another crucial point related to transaction costs. The proper number of members in a regime should be considered in order to avoid situations where an expanded or decreased number of members would vitiate its effectiveness. Since the NSG requires a consensus for any change of its rules, it is implausible that more participants will always lead the regime to 
being more effective. Member states have diverse opinions, which could hinder their ability to achieve consensus among themselves. Thus, an expanded NSG membership would decrease returns to scale rather increase them. In other words, the optimal size of a regime should only increase if the marginal costs of the regime to reach agreement and implement its rules declines as regime size grows. The regime should not expand its membership when the expansion would not reduce the marginal costs to anymore; rather, it raises the cost. In this light, it is highly necessary to examine the variables to see what is the optimal size of the NSG to guarantee its effectiveness.

Table 2. Transaction Costs: How to Maximize Regime Benefits

\begin{tabular}{|c|c|c|}
\hline & + (Effectiveness) & - (Limitations) \\
\hline $\begin{array}{l}\text { Issue Density \& } \\
\text { Complex Linkages }\end{array}$ & $\begin{array}{l}\text { - Emerging issues: dual-use equipment/ } \\
\text { facilities } \\
\text { - Necessity of keeping pace with } \\
\text { emerging nuclear technologies } \\
\text { - Export control system is highly related } \\
\text { with trading system and civilian } \\
\text { nuclear projects }\end{array}$ & \\
\hline $\begin{array}{l}\text { Provision of } \\
\text { Frameworks and } \\
\text { Forums } \\
\text { for Negotiation }\end{array}$ & $\begin{array}{l}\text { - Annual Plenary Meeting (1992-present) } \\
\text { - Seminars to improve NSG's } \\
\text { effectiveness } \\
\text { - Issue-based informal meetings } \\
\text { - Consultative Group (CG) }\end{array}$ & $\begin{array}{l}\text { - Limited chance to negotiate and } \\
\text { discuss with non-member states and } \\
\text { proliferators } \\
\text { - Activities of the NSG chair and } \\
\text { (unsuccessful) dialogues with non- } \\
\text { participating states in the margins of } \\
\text { international meetings }\end{array}$ \\
\hline $\begin{array}{l}\text { Optimal } \\
\text { Regime Size }\end{array}$ & $\begin{array}{l}\text { - Since decisions are made by } \\
\text { consensus, limited numbers of players } \\
\text { in NSG would increase or maintain } \\
\text { returns to scale }\end{array}$ & $\begin{array}{l}\text { - Problem of emerging supplier states } \\
\text { (Malaysia) } \\
\text { - Discussion of India/Pakistan's } \\
\text { membership in the NSG (non-NPT } \\
\text { states) }\end{array}$ \\
\hline
\end{tabular}

First, to analyze the NSG's effectiveness using the 'issue density' concept, it is necessary to consider the ultimate goal of the NSG and which specific issues would be handled under the export control regime. If the issues the NSG is dealing with are shown to have complex linkages, the issue density of the NSG is high, and that high issue density would substantiate the effectiveness of the NSG. It is a generally accepted idea that the most effective means to achieving non-proliferation is to control and restrict the export of nuclear items to dubious countries that have an intention to develop weapons. However, which items 
should be restricted under the regime to achieve the greatest effectiveness has been discussed in line with the development of nuclear technology. The NSG should keep pace with the evolving global security environment and rapidly developing nuclear-related industries.

Consideration of the nuclear technology under the regime's control is crucial to prohibiting the proliferation of nuclear weapons. The export control regime initially underlined the controls on nuclear materials and goods to be utilized for the further production of fissile materials. To control items on the guidelines that are likely to be used for weaponization has been emphasized to slowing nuclear proliferation; however, recalcitrant countries have attempted to use certain industrial products as items for weaponization. In this sense, the necessity to examine dual-use items led the NSG to create a second set of guidelines, and it is generally accepted that the most effective export control is to prevent dubious countries from constructing fissile materials production facilities with strict export controls over items sent to them. As items on the NSG guidelines has been expanded and updated, a high issue density of the NSG has ensued. The development of nuclear technologies and updates to the lists of dual-use items are closely linked with issues of science and trade. Close coordination among member states is necessary to resolve complex issues linked in complex ways.

Moreover, the NSG's other ultimate goal is promoting the peaceful use of nuclear energy. The NSG tries to encourage international trade and cooperation in the field of nuclear energy; it does not merely restrict the export of nuclearrelated materials and technologies. The NSG's rules and regulations do not hinder proper exports to be used in civilian nuclear projects and the production of nuclear energy. In this sense, the NSG should be closely linked not only with the governments of member states, but to each member's firms and corporations dealing with nuclear projects. Complex linkages are shown under the NSG regime: close relationships among the systems of international trade and the private sector is necessary to prevent the proliferation of nuclear weapons. In this light, there is a high issue density under the NSG regime. The issues of nuclear technology, trade to boost the good uses of nuclear energy, and the export of dual-use items are netted under the NSG regime in order to achieve non-proliferation. The issue density of the NSG is high. This definitely would be one of the crucial conditions to lead the NSG regime to becoming more effective. Figure 1 illustrates the issue density of the NSG and visualizes the complexity of the nuclear non-proliferation regime. 
Figure 1. NSG's Issue Density and Complexity ${ }^{4}$

\section{Issue Density of the Nuclear Export Control Regime}

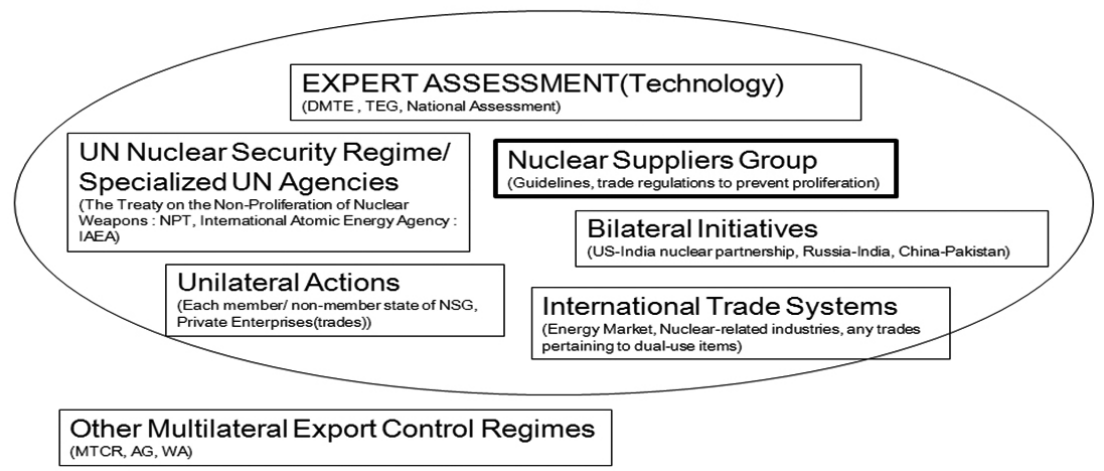

Note: Organizations surrounding the NSG illustrate the major institutions and initiatives pertaining to the NSG or the nuclear export control regime. Factors under the oval are relevantly and directly linked with the issue of non-proliferation and export controls; those elements affect the NSG's rule-making and mission in order to achieve nuclear non-proliferation and effective export controls of nuclear materials.

In view of the NSG's effectiveness, it is crucial to meet the sub-criterion of 'providing frameworks and forums for negotiation.' Meetings on either a regular or occasional basis allow NSG's member states to update guidelines and discuss the development of the NSG in an effective way. After a long silence, the NSG reactivated its plenary meetings from 1992, and these sessions have continued to the most recent meeting held in Bern in 2017. After the annual plenary meeting was reactivated, discussions on revising and updating the guidelines were also prodded. Providing a framework for negotiations allowed member states to revise Part 1 and Part 2 of the NSG guidelines several times through a thorough review and consultation. In addition, the NSG ultimately adopted new procedural arrangements for the sake of formalizing its membership and improving the effectiveness of its operations in 1993 after the regularization of plenary meetings. Another regular meeting provided by the NSG is the NSG Consultative Group (CG), which is a working-level deliberative body to handle all cross-cutting issues related to the NSG's guidelines. Members of the CG meet

4 The contents of Figure 1 were updated to reflect the analysis and resources pertaining to the NSG and based on the basic structure and elements of the regime, which depicts the complexity of the international climate change regime (Keohane and Victor 2011). 
at least twice a year, and the substantive talks in those regular meetings make a positive contribution to handling the complex issue linkages with technical matters and nuclear exports. Moreover, informal and occasional meetings also are held under the NSG regime. Seminars to improve the NSG's effectiveness are an example. Experts and specialists on export controls gather to discuss how to define the NSG's roles and resolve issues of transparency. Issue-based informal meetings are held under the NSG, and those occasional meetings also contribute to the provision of frameworks and forums for deliberative consultations. The regular and occasional meetings under the NSG allow member states opportunities to discuss the guidelines and effective means to hinder proliferation. However, there is still little opportunity to have a discussion with states that are not members of the NSG. Since serious violations of NSG's rules tend to emerge outside the NSG, imposing the responsibilities on states outside the NSG membership is highly necessary for the regime's success. There have been efforts by the NSG chair to open dialogues with non-member states but the results have not been encouraging. The NSG chair contacted nonmember states during other international meetings, such as IAEA conferences (Anthony Ahlström and Fedchenko 2007), and NSG directly asked for opening a dialogue with Indonesia, Malaysia, and Mexico, and showed its intention to initiate talks with transshipment states in its 2001 plenary meeting. However, the efforts of the chair did not result in significant and substantive meetings with non-member states. In addition, there have been several group efforts to subsume non-member states into the regime. The "Statement on Civil Nuclear Cooperation with India" adopted by the NSG is understood in the same sense. According to the NSG's annual plenary meeting press report of 1994, there was a request to the NSG chair to conduct a series of briefings for nonmembers. The most viable option to include non-member states into the NSG's negotiating frameworks and its forums is through membership expansion. It is directly linked to the next sub-criterion to analyze the effectiveness of the NSG: optimal regime size.

Table 3. Expansion of NSG Membership ${ }^{5}$

\begin{tabular}{c|c|c}
\hline Year & Numbers of Participants & Observers \\
\hline 1977 & 7 & \\
\hline 1982 & 17 & \\
\hline
\end{tabular}

\footnotetext{
${ }^{5}$ The contents of this table are updated from the yearly Public Statements of NSG plenary meetings.
} 


\begin{tabular}{|c|c|c|}
\hline 1987 & 23 & \\
\hline 1992 & 27 & \\
\hline 1993 & 29 & $\begin{array}{l}\text { Argentina (member state in 1997); Commission of the } \\
\text { European Communities (Permanent) }\end{array}$ \\
\hline 1997 & 34 & \\
\hline 2000 & 38 & Slovenia (member state in 2001) \\
\hline 2001 & 39 & \\
\hline 2002 & 40 & \\
\hline 2004 & 44 & \\
\hline 2005 & 45 & \\
\hline 2009 & 46 & Chair of the Zangger Committee \\
\hline 2011 & 46 & $\begin{array}{l}\text { Chair of the Zangger Committee (became Permanent } \\
\text { Observer) }\end{array}$ \\
\hline 2013 & 48 & \\
\hline
\end{tabular}

The enlargement of NSG membership was considered a crucial goal of the regime. As Table 2 illustrates, participation in the NSG has significantly expanded, and there are particular institutions that are permanent observers, and some states that participated as observers became member states the following year or after. To control illegal exports effectively, the group requires more member states to comply with its rules and guidelines. However, enlarging membership does not always result in maximization of returns to scale. If all member states have the same interests in the nuclear trade and non-proliferation of nuclear weapons, the enlargement of the NSG would no longer be so problematic. This condition must be met, but rebuttal by a copious number of empirical case seems to indicate that various countries have their own interests and diverse points of view on the issue.

Expanded membership would make it more difficult for the NSG to reach consensus. Since the NSG requires consensus from all members to update guidelines and make decisions on crucial issues, an expanded membership with various unrelated interests would not enhance the effectiveness of the NSG, but rather it would vitiate it. In addition, a major concern is that admitting countries that have not joined the NPT and states where the implementation of export controls is inadequate, would rather weaken the accountability of the regime and the current high standards of the NSG guidelines (Thränert and Bieri 2013). In this sense, the optimal size of the regime would suggest that the current, limited numbers of players in the NSG should be interpreted as a positive point. 
Notwithstanding the opposition to expanding membership to maximize the regime's returns to scale, discussion on new NSG membership is ongoing. This is understood as an effort to make emerging supplier states get involved under the regime for the sake of spreading adherence to the export control norms of the NSG. The necessity of expanding membership to emerging suppliers was strongly emphasized when it was uncovered that the Malaysian company SCOMI had exported high-precision aluminum centrifuge parts to Libya. Although Malaysia is a signatory to the NPT, SCOMI played a key role in the A. Q. Khan network. According to a report by Malaysian police, SCOMI Precision Engineering did not break Malaysian law or even violate the NPT, as it claimed that the exported nuclear equipment to Libya was not on the listed items of the NPT (Blackford 2005). The Malaysian case alerted the international community to the need to spread the NSG guidelines through substantive advice to the emerging supplier states and extending membership to those emerging suppliers, such as Malaysia, should not be ignored. However, the matter of returns to scale also should be considered when dealing with emerging supplier states. Since the NSG's guidelines and rules are implemented voluntarily with no enforcement, there is no guarantee that all emerging suppliers will become new members of the NSG and will comply with the regime's obligations (Blackford 2005).

In addition, a potential problem has emerged that membership extension would become a much more serious issue when candidates were not signatories of the NPT and acted in violation of NSG guidelines and rules. India and Pakistan are two crucial membership candidates, but the efforts of those de-facto nuclear states to win the support of most NSG members became a contentious and controversial issue. The possibility of two countries not signatories to the NPT being admitted as member states of the NSG cannot be neglected. If the two states are accepted as members of the NSG, there would be strong criticism of that decision. The participation of recalcitrant countries in the nonproliferation regime foments concerns among other member states. It is believed by many that the two countries' participation in the NSG would weaken the accountability of the organization, the high standards of its guidelines, and even the effectiveness of the export control regime in the long run.

\section{NSG'S EFFECTIVENESS AND LIMITATIONS: AN ANALYSIS OF INFOR- MATION AND TRANSPARENCY}

Sharing high-quality information within a regime is required to raise the effectiveness of the regime. A high-transparency regime is achievable when the regime reduces information costs and resolves the uncertainty issue. There are 
three big obstacles hampering regime effectiveness: asymmetrical information, moral hazard, and irresponsibility (Keohane 1984). If those areas of difficulty exist, they would severely hinder the cooperative behavior of member states. If the regime is able to obviate those obstacles, it raises the regime's effectiveness in terms of successful information sharing and transparency.

The sub-criteria to analyze the transparency of the NSG and its information sharing systems are basically determining 1) whether the NSG has a highly regularized information sharing systems; 2) whether the NSG sponsors organized regular meetings of expert groups to update information and maintain a high-quality of information; and 3) whether there is strong participation by those states that possess a large amount of information. The first and second criteria are linked to 'how to obviate the asymmetrical information issue under the NSG and the export control regime.' The problem of asymmetric information is highly likely to cause dishonest behavior among regime members, which seriously hampers the regime's effectiveness. A process of upgrading the general level of available information is required for greater transparency of the regime. The first criterion analyzes whether the information sharing systems of the NSG are 'regularized' and whether continuous information sharing is viable. The second criterion is linked with 'how to provide high-quality information about the export control regime to member states.' Providing high-quality information is a cornerstone to mitigating the risks of uncertainty and address the issue of asymmetrical information.

The last sub-criterion elucidates the means of resolving the 'irresponsibility' problem. Even though member states become full members of the regime, that does not guarantee that those countries will make a strong commitment to raising the regime's effectiveness. In terms of information sharing within the regime, strong incentives such as sharing research and the development of information on irresponsible countries, are necessary. According to Keohane (1982), the participation of information-strong countries is one of the incentives for information-weak states to participate actively under the regime (Keohane 1982).

Moral hazard, which has been described as one of the major obstacles to the regime's successful sharing of information and achieving greater transparency in previous literature on international regimes, has not been considered as a subcriterion for measuring the effectiveness of the regime. It is possible to assume that some countries ensnared in the moral hazard problem might provide fabricated information with the intention to undercut data and falsify statistics related to their export controls. The moral hazard issue would certainly hinder the effectiveness of the NSG; however, it is hard to detect wrong or falsified 
information on a case-by-case basis. Moreover, it is believed that states with moral hazard are more likely to conceal their intentions and bury accurate data, but there is not enough data or statistics to analyze 'moral hazard' as subcriterion. Moral hazard itself is a significant limitation on the NSG's further progress, so this issue will be explicated in the conclusion of this paper.

Table 4. Information: How to Achieve Regime Transparency

\begin{tabular}{|c|c|c|}
\hline & + (Effectiveness) & - (Limitations) \\
\hline $\begin{array}{l}\text { Highly Regularized } \\
\text { Information-sharing } \\
\text { System } \\
\text { (Resolution } \\
\text { of asymmetrical } \\
\text { information issue) }\end{array}$ & $\begin{array}{l}\text { - Communications through a Point of } \\
\text { Contact (POC) } \\
\text { - NISS (NSG Information Sharing } \\
\text { System) } \\
\text { - E-mailing routinely to share } \\
\text { information in real-time } \\
\text { - Annual Information and Exchange } \\
\text { Meeting (IEM) and Licensing and } \\
\text { Enforcement Expert Meeting (LEEM) } \\
\text { - Sharing good practices among NSG } \\
\text { member states }\end{array}$ & $\begin{array}{l}\text { - No regularized information sharing } \\
\text { system with other non-proliferation } \\
\text { regimes (e.g IAEA) }\end{array}$ \\
\hline $\begin{array}{l}\text { Organized } \\
\text { Technical Expert } \\
\text { Groups Update } \\
\text { Information } \\
\text { and Maintain } \\
\text { a High-quality } \\
\text { of Information }\end{array}$ & $\begin{array}{l}\text { - Dedicated Meeting of Technical } \\
\text { Experts (DMTE, 2010) group to } \\
\text { conduct three-year fundamental } \\
\text { review of the two control lists } \\
\text { - Technical Experts Group (TEG, } \\
2013 \text { ) to review and make } \\
\text { recommendations on technical } \\
\text { questions }\end{array}$ & $\begin{array}{l}\text { - The issue of how to maintain } \\
\text { momentum on the project to update } \\
\text { control lists remains unsettled }\end{array}$ \\
\hline $\begin{array}{l}\text { Active Participation } \\
\text { in Information } \\
\text { Sharing by Strong } \\
\text { States }\end{array}$ & $\begin{array}{l}\text { - Active participation of strong states } \\
\text { (Japan, United States, Germany) }\end{array}$ & $\begin{array}{l}\text { - Some member states' reluctance } \\
\text { to participate in sharing information } \\
\text { (China) }\end{array}$ \\
\hline
\end{tabular}

To raise the effectiveness of, and avoid loopholes in, the export control regime, it is required to share the information about which cases are denied, which items are updated in the control lists, and which technologies and goods are catalogued as dual-use items. A highly-regularized information sharing system is necessary to the frequent sharing of information, and in real-time, and Japan as the Point of Contact is the cornerstone to filling a significant information gap in the nuclear export control regime. The participants in the 1992 Warsaw meetings accepted Japan's offer to serve as the POC. The Permanent Mission of Japan distributes NSG documents and notifies NSG members of meeting 
schedules.

In addition to Japan's dedication to the sharing of information under the NSG regime, other regularized and systematic information sharing systems and meetings were created for the sake of a quick exchange of information. This was strongly expected to mitigate situations of asymmetric information among member states. The NSG Information Sharing System (NISS), the Annual Information and Exchange Meeting (IEM), and the Licensing and Enforcement Expert Meeting (LEEM) are all elements of the information sharing systems operated under the NSG regime. The NISS was created in response to the need for sharing accurate information in a timely manner. Thus, the U.S. Department of Energy sponsored the development of the NISS, a computerized information sharing system among all member states of the NSG. Granting member states quick-access to a wide range of technological information and policy options contributed to NSG effectiveness. Since this is a computerized and systemic information sharing system, it is able to provide secure electronic mailing. This mailing system not only provides documents and records but also has become an informal channel of communication (Dedik et al. 1995). The NISS works as a means of denial reporting by reporting export denial notifications to NSG member states within two days on average. Moreover, data retrieved from this system is conducive to identifying the patterns of interactions of proliferators and detect anomalous cases, including the export of controlled items to countries for which concerns about safeguards compliance exist (U.S. General Accounting Office 2002).

The Information and Exchange Meeting (IEM) and the Licensing and Enforcement Experts Meeting (LEEM) are NSG-sub meetings that are held once a year during Plenary Week. The IEM is organized to share general information about the goals of the NSG guidelines and its contents. Subjects of discussion under the IEM include the right approach to nuclear technological developments and the correct policies to handle issues relevant to the export of those materials and technology. On the other hand, LEEM specializes in legal issues, such as each member state's national experiences regarding licensing practices and prosecutions and law enforcement actions for export control violations. The LEEM is a part of IEM meetings and summary reports of discussions in the LEEM are subsumed within the report of IEM.

The most recent improvement under the NSG regime to resolve the problem of asymmetric information is publishing 'The Good Practices for Brokering \& Transit/Transshipment' on the NSG website. The decision to publish was made at the 2014 NSG plenary meeting in Buenos Aires. From the view of the export control regime, 'brokering' and 'transit/transshipment' are actions that are 
closely related to trading relations across borders. The project to report best practices was mandated by Germany, and this ambitious project was completed with various documents and resources provided by other participating governments. Albeit, those good national practices are not legally binding, but they are able to assist other governments under the regime in updating their national systems to control items effectively and develop better supervision of brokering and transit/transhipment.

Although the NSG has developed its own information sharing systems, it still faces systematic limitations that must be resolved and considered as urgent tasks. Information sharing systems among NSG member states have been created, but no regularized information sharing systems with other nonproliferation regimes currently exist. To regulate the items on the NSG control lists successfully, coordination and information sharing with other nonproliferation regimes are crucial factors to achieving the NSG's final goal of nonproliferation. A specific case can be found in the relationship between the NSG and the IAEA. The public statement of the NSG plenary meeting in Prague in 2013 indicated that, if NSG member states adopted amendments to the NSG control list in its annual plenary meeting, the NSG would request the IAEA later to publish the updated version of the list. Albeit, a regularized information sharing system is necessary for the sake of quick and efficient sharing of information, but the NSG does not share denial information with the IAEA (Hibbs 2011). Information shared with the IAEA will capitalize on implemention of the Additional Protocol among IAEA member states; thus, an information sharing system would strongly assist the IAEA, and that assistance would raise the NSG's voice in the decision-making process, especially with regards to issues of nuclear transfers and its influence on the whole non-proliferation regime. Furthermore, the IAEA's larger membership could provide copious information about the countries for which there are safeguards compliance concerns. Notwithstanding the benefits of cooperation with other non-proliferation organizations, the governments of NSG member states are less likely to provide denial information to the IAEA because of concerns that the information would be leaked to other IAEA member states that are not NSG members, or countries that are the subject of the NSG's denial (Hibbs 2011). The NSG should calculate the benefits and costs from a regularized information sharing system with other nonproliferation systems, but it is certain that a multilayered cooperation structure with other regimes is necessary to achieve the NSG's ultimate goal. As described above, the NSG has developed to operate organized information systems and to hold regular meetings since the plenary meeting was reactivated. The efforts of the NSG are meaningful to mitigating the problems of asymmetric information 
among the member states. Notwithstanding the lack of information systems with other non-proliferation organizations, such as the IAEA, the NSG's continued efforts to create that system and organize meetings to reduce information costs are vital to the NSG effectiveness.

In order to improve transparency in the regime, not only achieving a regularized information sharing system, but also the quality of the information shared should be considered. In view of the effectiveness of the NSG's information sharing system, an organized knowledge and technology sharing system is crucial. The rapid development of nuclear technology and technical innovations in other fields influences the export control lists and forces the NSG to be aware of progress in new technologies when it updates its control list. Updating the NSG's control list is concomitant with technical advancements and up-to-date technologies. To reach this significant goal, the NSG agreed to form the Dedicated Meeting of Technical Experts (DMTE) group in 2010, and in 2013 the Technical Experts Group (TEG) was created . First, the DMTE group conducted a three-year fundamental review of the two NSG guidelines and updated control lists to be concomitant with technical advancements, newly emerged security challenges, and changing market trends in the nuclear industry. After a three-year discussion, the DMTE suggested 54 proposals to change the control list, and an agreement on updating the control list was passed by the plenary meeting. The NSG organized the Technical Experts Group (TEG) as a standing body to implement the work that the DMTE carried on, and it aimed to discuss and make recommendations to the Consultative Group, especially on technical issues. The TEG meetings are held at least once a year. The two NSG guidelines were revised and re-published in 2016, once again after completing another three-year review process.

The NSG's efforts to update guidelines based on member states exchanging views and agreeing on a number of proposals was a meaningful process. To get a 'high-quality of information,' it is necessary to regularly update the guidelines so that the NSG can provide crucial information to member states and even the public. The process of updating the guidelines required an exceptional amount of time, effort, and resources, with the enthusiastic participation of the memberstate governments (Onishi et al 2016). During the three-year review process, the NSG and its bodies worked interactively to keep pace with fast-changing technologies. Prodigious resources should be put into the process and various technical experts should participate in updating the NSG control lists and checking for technological developments in the nuclear industry. Although the two previous fundamental reviews of the NSG's guidelines have been deemed successful, that momentum for the fledgling TEG meeting should be maintained. 
As described above, it is strongly emphasized that the active participation of information-strong states, which have large amounts of higher-quality information, is required to develop and upgrade available information under the regime. However, the biggest concern for the continued provision of high quality information is the irresponsibility of some member states; that is, the risk of members free-riding under the regime. The risk of free-riding also should be obviated in order to raise the effectiveness of the regime. All NSG member states recognize that positive momentum from the fundamental review should be carried forward for the sake of both maintaining the high quality of information and mitigating the risk of free-riding. Of course, if there are some free-riders, it is a difficult task to persuade them, especially when they are faced with uncertainty.

The irresponsibility of member states is also directly linked with the third subcriterion: the active participation of information-strong states. The contributions of the information-strong states are found in the history of the NSG's information sharing systems and its meetings, as illustrated in the analysis of the first sub-criterion, a highly regularized information sharing system. The first example is Japan. An original member of the NSG from the first meeting in 1975, Japan has taken a positive role as Secretariat to support the NSG guidelines since 1995. More importantly, it has taken charge of playing the role of Point of Contact (POC) (Takako and Remacle 2008). The POC is the most basic system to share information about export controls under the NSG, and it has become a cornerstone of, and a strong motivation to, the development of several NSG information sharing systems. Moreover, the U.S. government's sponsorship to establish a computerized information sharing system enable the NSG to have a secure networked database and provide real-time information to member states. The Los Alamos National Laboratory in the United States built the NISS, and the benefits of the NISS as described above include the rapid dissemination of information, such as denial information and transfer of proliferation-sensitive materials and technology, and the prevention of irregular and illegal trades of restricted equipment and items (Louka 2011).

Lastly, the government of Germany is one of the most active informationstrong countries. The project to publish 'The Good Practices for Brokering \& Transit/Transshipment' on the NSG website was mandated by Germany's full commitment and the assistance of other member states. The active participation of those information-strong states and their responsible actions have allowed the NSG to improve its effectiveness. The responsible participation of those countries is motivation or an incentive for other member states to maintain the NSG regime. These strong commitments of participating governments 
such as Japan, the United States, and Germany is necessary to having greater transparency inside the group. However, not all member states are actively participating to improve the transparency under the NSG regime.

Some states that are required to disclose information are highly reluctant to share their information at a significant level. They fail to participate in meetings even though representatives of those countries attend the meetings. Their patterns of behavior have been criticized because those countries are not sharing information under the NSG; but rather, are attending the NSG's meeting to access information (Hibbs 2011). China is mentioned by several member states as one of countries that has been reluctant to share information relevant to its export control policies and records. It is undeniable that the active participation of information-strong states in the process of information sharing is conducive to the effectiveness of the regime; however, the lack of participation by other information-strong state, such as China, is a limitation to the improvement of the NSG's transparency and its effectiveness in the long-run. If only five or six countries provide the same information to the regime, ongoing improvement of the regime's transparency cannot be achieved.

\section{CONCLUSION}

The NSG regime's effectiveness here has been evaluated using functional theories. The categories of legal liability, transaction costs, and information sharing (uncertainty issue) are what the major functional theorists have suggested in previous studies should be applied to analyze the effectiveness of the Nuclear Suppliers Group. Moreover, the specific three sub-criteria defined in each category are based on the meticulous study of functional theory and a review of the export control regime's particular characteristics thoroughly.

The most salient point of the analysis of the NSG regime using functional theories is that there is substantial evidence of the Nuclear Suppliers Group's effectiveness. According to this analysis, the high issue density and NSG's complexity in the second categories, and the NSG's significant systematic improvements, especially found in the second and third categories, raised the effectiveness of the export control regime. Reduced transaction costs and an improved information sharing system, which is concomitant with the development of the regime, has been explicated as one of the crucial elements leading the NSG to becoming more effective. However, still there are some limitations to the NSG. Below is a substantive summary of the benefits the NSG has achieved and the risks the NSG has faced. 
In terms of legal liability, the NSG's long-time efforts to establish strong legal liability is meaningful; the regime and its member states were strongly encouraged to place an embargo upon recalcitrant countries, and the group has updated its guidelines. NSG's legal advice or model regulations for member states to provide various models for domestic law and regulation is crucial for implementation to encourage accountability among member states. However, there are still significant limitations to meeting the legal liability standards. Several exceptional cases, such as China's exports to Pakistan and Russia's nuclear exports to India, harmed the integrity of the NSG regime. In this sense, the NSG should better clarify how the guidelines are to be interpreted and applied among the participating states. Moreover, the application of the NSG's rules and regulations to its member states is dependent on the member states' discretion. To increase its ability to impose sanctions, the NSG should intensify cooperation with the UN Security Council's Resolution 1540 Committee to strengthen the legal binding of NSG regulations on member states (Hibbs 2011).

Next, considering that the issue density of the export control regime is high and has complex issue linkages, the NSG regime is highly likely to be maintained. Furthermore, NSG had vigorously pursued efforts to strengthen the regime's procedures and standards throughout its history by providing forums and numerous meetings for negotiations to promote progress. However, the issue of the regime's membership is unresolved. Talks with non-member states should be initiated to achieve one of the crucial non-proliferation goals, even though this sometimes violates some standards related to the regime's effectiveness, such as regime integrity and its optimal size. This is a dilemma for the regime. There is a strong need to substantively negotiate over the 'membership' issue under the regime. Developing clear standards for full membership is urgently needed to improve the regime's effectiveness and avoid frictions among member states.

The NSG also has shown its innovativeness through efforts to improve its effectiveness in terms of 'information sharing.' The introduction of a cuttingedge information system is one of the most important areas of progress under the regime. The computerized and systematic system to share highquality information has become a cornerstone of the group in order to reduce uncertainty under the NSG regime. Moreover, regular meetings to discuss substantive issues with nuclear technology experts and policymakers has been one means to raising the regime's effectiveness in terms of information sharing. Notwithstanding the reluctance of some recalcitrant countries to share their information, newly built systems and mechanisms under the regime represent meaningful progress in the NSG. 
Lastly, to address the NSG's 'transparency' issue, the quality of information, the effectiveness of the information sharing system, and also the 'moral hazard' issue-one of the criteria Keohane (1982) suggested for assessing transparencyneed to be discussed systematically. However, a lack of information and data needed to calculate the 'moral hazard' of export controls makes it difficult to do a meaningful study. Since the regime's rules and regulations are not legally binding, it is also hard to resolve the irresponsibility and moral hazard of member and non-member states, collectively. Against this backdrop, a plausible conclusion on the moral hazard issue of the NSG is that there is no shortcut to fixing an individual state's violations of international nuclear policy to be compliant with the NSG's export control regime. Regular, ongoing talks and negotiations within the regime to reduce that uncertainty would be a stepping stone to mitigating the moral hazard issue under the regime. Progress to achieve the NSG's ultimate goal of non-proliferation has been painful, but there is no other way but to move forward.

\section{REFERENCES}

Anthony, Ian, Christer Ahlström, and Vitaly Fedchenko. 2007. Reforming Nuclear Export Controls: The Future of the Nuclear Suppliers Group. Oxford, UK: Oxford University Press.

Blackford, Jacob. 2005. "Multilateral Nuclear Export Controls After the AQ Khan Network." Paper presented at the Institute for Science and International Security (ISIS) (January 13).

Buchanan, Allen, and Robert O. Keohane. 2006. "The Legitimacy of Global Governance Institutions." Ethics \& International Affairs 20(4), 405437.

Dedik, T., R.S. Goorevich, and C.E. Thorne. 1995. The Nuclear Suppliers Group Information Sharing (NISS): Putting Technology to Work for a More Effective and Efficient Supplier Arrangement. Chicago, IL: Inst. of Nuclear Materials Management.

Fuhrmann, Matthew, and Yonatan Lupu. 2016. "Do Arms Control Treaties Work? Assessing the Effectiveness of the Nuclear Nonproliferation Treaty." International Studies Quarterly 60(3), 530-539.

Haggard, Stephan, and Beth A. Simmons. 1987. "Theories of International Regimes." International Organization 41(3), 491-517.

Hibbs, Mark. 2011. The Future of the Nuclear Suppliers Group. Washington, DC: Carnegie Endowment for International Peace. 
International Atomic Energy Agency. 2008. "Communication dated 10 September 2008 received from the Permanent Mission of Germany to the Agency regarding a 'Statement on Civil Nuclear Cooperation with India'.” IAEA (September 19). Accessed at https://www.iaea.org/sites/ default/files/publications/documents/infcircs/2008/infcirc734c.pdf (October 7, 2017).

Keohane, Robert. O. 2005. After Hegemony: Cooperation and Discord in the World Political Economy. Princeton, NJ: Princeton University Press. . 1982. "The Demand for International Regimes." International Organization 36(2), 325-355.

Keohane, Robert O., and David G. Victor. 2011. "The Regime Complex for Climate Change." Perspectives on Politics 9(1), 7-23.

Kerr, Paul. 2007. "China Updates Nuclear Export Regulations." Arms Control Association (January 1). Accessed at https://www.armscontrol. org/2007_01-02/ChinaUpdate (October 11, 2017).

Levy, Marc A., Oran R. Young, and Michael Zürn. 1995. "The Study of International Regimes." European Journal of International Relations 1(3), 267-330.

Louka, Elli. 2011. Nuclear Weapons, Justice and the Law. Cheltenham, UK: Edward Elgar Publishing.

McGoldrick, Fred. 2011. "The Road Ahead for Export Controls: Challenges for the Nuclear Suppliers Group.” Arms Control Today 41(1), 30.

Nuclear Suppliers Group. 1992. "Press Statement of Nuclear Suppliers Meeting: Meeting of States Adhering to the Nuclear Suppliers Guidelines." NSG (April 3). Accessed at http://www.nuclearsuppliersgroup.org/images/ Files/Documents-page/Public_Statements/1992-Press.pdf (November 9, 2017). . 1994. "Annual Plenary Meetings Press Report, 1994." NSG (April 14). Accessed at http://www.nuclearsuppliersgroup.org/images/Files/ Documents-page/Public_Statements/1994-Press.pdf (November 7, 2017).

. 1997. "International Seminar on the Role of Export Controls in Nuclear Non-Proliferation." NSG (October 7-8). Accessed at http:// www.nuclearsuppliersgroup.org/images/Files/Documents-page/ publications/SeminarControl1.pdf (June 7, 2017).

. 1999. "2nd NSG International Seminar on the Role of Export Controls in Nuclear Non-Proliferation.” NSG (April 8-9). Accessed at http:// www.nuclearsuppliersgroup.org/images/Files/Documents-page/ publications/SeminarControl2.pdf (June 8, 2017). 
2013. "Public Statement (Final) Plenary Metting of the Nuclear Suppliers Group." NSG (June 13-14). Accessed at http://www. nuclearsuppliersgroup.org/images/Files/Documents-page/Public_ Statements/2013-06-Prague-NSG_6_PUBLIC_STATEMENT_HOD_ final.pdf (October 29, 2017).

. 2014. "Brokering and Transit/Transshipment in the Context of the NSG." NSG (June 26-27). Accessed at http://www. nuclearsuppliersgroup.org/images/Files/National_Practices/ National_Good_Practices.pdf (July 16, 2017). . 2015. "Review Conference of the Nuclear Non-Proliferation Treaty." NSG (May 6). Accessed at http://www.nuclearsuppliersgroup.org/ images/NSGChairCGChairRevConPresentation.pdf (June 13, 2017).

Onishi, Takashi, et al. 2016. "Nuclear Safeguards and Non-proliferation." In Luciano Maiani, Said Abousahl, and Wolfango Plastino eds., International Cooperation for Enhancing Nuclear Safety, Security, Safeguards and Non-proliferation. New York, NY: Springer International Publishing, 15-30.

Paddock, Carl. 2009. India-US Nuclear Deal: Prospects and Implications. Guwahati, India: Epitome Books.

Rathjens, G. 1998. "Nuclear Proliferation Following the NPT Extension." In R.G.C. Thomas ed., The Nuclear Non-Proliferation Regime. London, UK: Palgrave Macmillan, 25-40.

Sagan, Scott D. 2011. "The Causes of Nuclear Weapons Proliferation." Annual Review of Political Science 14, 225-244.

Thränert, O., and M. Bieri. 2013. "The Nuclear Suppliers Group at the Crossroads." CSS Analysis in Security Policy 127.

Ueta, Takako, and Eric Remacle. 2008. eds., Tokyo-Brussels Partnership: Security, Development and Knowledge-based Society. Bern, Germany: Peter Lang.

United Nations, Department for Disarmament Affairs. 2005. "The Treaty on the Non-Proliferation of Nuclear Weapons." United Nations (May 11). Accessed at http://www.un.org/en/conf/npt/2005/npttreaty.html (October 6, 2017).

U.S. General Accounting Office (GAO). 2002. "Nonproliferation Strategy Needed to Strengthen Multilateral Export Control Regimes." U.S. GAO (October 25). Accessed at http://www.state.gov/documents/ organization/14867.pdf (October 13, 2017). 